\title{
ACCESO Y PARTICIPACIÓN DE LOS PUEBLOS INDÍGENAS EN EL SISTEMA DE MEDIOS DE ARGENTINA
}

\section{Access and Participation of Indigenous Peoples in Argentina's Media System}

\section{Acesso e participação dos povos indígenas no sistema de meios da Argentina}

María Magdalena Doyle, Universidad Nacional de Córdoba, Argentina

magdalenadoyle@gmail.com

Recibido: 15 de marzo de 2017

Aprobado: 25 de enero de 2018

\section{RESUMEN}

La Ley de Servicios de Comunicación Audiovisual, sancionada en Argentina en 2009, reconoce el derecho a la comunicación de los pueblos originarios. Sin embargo, las luchas indígenas en torno a su participación en el sistema de medios se remontan a mucho antes, ya que tienen más de tres décadas y se inscriben en modalidades históricas de 'inclusión' de los indígenas en la nación.

Aquí proponemos analizar los antecedentes de la presencia indígena en la Ley de sca: las trayectorias de sus luchas por derechos a la comunicación y las políticas públicas que, antes de la sanción de la ley, promovieron la participación indígena en los medios. Luego, nos detenemos en la modalidad de inclusión de los pueblos originarios en la ley y los debates en torno a ello, recuperando principalmente la perspectiva indígena. Analizamos las principales transformaciones que ocurrieron a partir de la sanción de la ley en lo que refiere al acceso y participación indígena en el sistema de medios. Y, finalmente, señalamos algunos desafíos que enfrentan las comunidades que gestionan 
medios de comunicación, a partir de las transformaciones políticas que tienen lugar desde diciembre de 2015 por el cambio de gobierno en Argentina.

Palabras clave: medios de comunicación, pueblos indígenas, derechos a la comunicación.

\begin{abstract}
The Law of Audiovisual Communication Services, sanctioned in Argentina in 2009, recognizes the right to communication of indigenous peoples. However, the indigenous struggles over their participation in the media system date back much earlier, since they have been in existence for more than three decades and are part of the historical 'inclusion' modalities of indigenous peoples in the nation.

Here we propose the analysis of the antecedents of the indigenous presence in the Acs Law: the trajectory of indigenous struggles for communication rights and public policies that, prior to the enactment of the law, promoted indigenous participation in the media. Then we stop in the inclusion modality of the indigenous peoples in the law and the debates around it, recovering mainly the indigenous perspective. We analyze the main transformations that occurred after the enactment of the law in what refers to indigenous access and participation in the media system. Finally, we point out some challenges faced by the communities that have media, since the political transformations that have taken place since December 2015 due to the change of government in Argentina.
\end{abstract}

Keywords: Media, indigenous peoples, rights to communication.

\title{
RESUMO
}

A Lei de Serviços de Comunicação Audiovisual, sancionada na Argentina em 2009, reconhece o direito à comunicação dos povos originários. No entanto, as lutas indígenas em torno à sua participação no sistema de meios se remontam a muito antes, já que tem mais de três décadas e se inscrevem em modalidades históricas de 'inclusão' dos indígenas na Nação.

Aqui propomos analisar os antecedentes da presença indígena na Lei scA: as trajetórias das suas lutas por direitos à comunicação e às políticas públicas que, antes da sanção da Lei, promoveram a participação indígena nos meios. Depois detemo-nos na modalidade de inclusão dos povos originários na Lei e os debates em torno a isto, recuperando principalmente a perspetiva indígena. Analisamos as principais transformações que ocorreram a partir da sanção da Lei no que refere ao acesso e participação indígena no sistema de meios. E, finalmente, assinalamos alguns desafios que enfrentam as comunidades que administram meios de comunicação, a partir das transformações políticas que têm lugar desde dezembro de 2015 pela mudança de governo na Argentina.

Palavras chave: meios de comunicação, povos indígenas, direitos à comunicação. 


\section{DISERTACIONES}

ESTUDIOS

Comunicación indígena en América Latina

ISSN: 1856-9536

Doi: http://dx.doi.org/10.12804/revistas.urosario.edu.co/disertaciones/a.5479

Volumen 11, Número 2 / Julio-diciembre 2018

Versión PDF para imprimir desde

http://revistas.urosario.edu.co/index.php/disertaciones

En 2009, durante la discusión del Proyecto de Ley de SCA, muchas organizaciones indígenas demandaron que sus pueblos fuesen asumidos (por el Estado y la sociedad toda) como sujetos de derecho en relación con los medios. Ese fue un momento central, tanto en Argentina como en toda América Latina, por los debates que se generaron y las transformaciones que luego tuvieron lugar en términos de reconocimiento político y jurídico de los indígenas como sujetos con derecho a definir cómo ser vistos y oídos en el sistema de medios, y a participar en la definición de las normas que regulan dicho sistema (Doyle, 2015; Lizondo, 2015).

A su vez, esa irrupción política no puede comprenderse sino en el marco de los tiempos largos de la violenta incorporación indígena en el Estado argentino, de la configuración hegemónica del sistema de medios y de las luchas de los pueblos originarios por tener voz en el espacio público mediatizado.

En función de ello, el objetivo del presente artículo es analizar aquella irrupción indígena que disputa derechos a la comunicación, pero inscribiéndola en la historia de configuración del sistema de relaciones interétnicas a nivel nacional, en el cual este sector de la población ha ocupado siempre un lugar de subalternidad, pero a la vez ha luchado por revertir esa posición.

Para este abordaje, además de recuperar bibliografía antropológica relativa a la configuración social, política y económica de la diversidad étnica de la nación, desarrollamos un trabajo de campo etnográfico (Guber, 2001) desde 2009 a 2016, en el cual estudiamos la lucha indígena por el derecho a la comunicación, antes, durante y después de la sanción de la Ley de sca. Específicamente, realizamos entrevistas en profundidad a comunicadores(as) indígenas que en 2009 fueron parte del Encuentro Nacional de Organizaciones Territoriales de Pueblos Originarios (ENOTPO), organización supracomunitaria que nucleó a más de 50 organizaciones y comunidades, y que en 2009 impulsó la inclusión del indígena en la ley; observación participante en eventos en que ellos plantearon sus posturas respecto de su derecho a la comunicación -encuentros nacionales de comunicadores(as) indígenas, conferencias de prensa del ENOTPo y presentaciones en la Cámara de Diputados de la Nación efectuadas por los(as) indígenas en 2009-; y revisión de documentos por ellos producidos (declaraciones, folletos, presentaciones de Power Point). ${ }^{1}$

1 Este artículo es parte de la investigación doctoral propia, desarrollada en el Doctorado en Antropología de la Universidad de Buenos Aires y concluida en 2016, titulada "El derecho a la comunicación de los pueblos originarios. Límites y posibilidades de las reivindicaciones indígenas en relación con el sistema de medios de comunicación en Argentina". En dicha investigación analizamos las condiciones para el ejercicio del derecho a la comunicación por parte de los pueblos indígenas en el marco de la contemporánea configuración hegemónica del espacio público mediatizado en Argentina, y estudiamos las intervenciones que distintas experiencias organizativas indígenas desarrollan para la reivindicación de ese derecho. Se trató de una investigación de enfoque etnográfico desarrollada entre 2009 y 2016, en la cual abordamos tanto los debates que las organizaciones supracomunitarias indígenas plantearon a nivel nacional en el período de discusión del Proyecto de Ley de SCA (principalmente el ENOTPO), como también el modo en que esas discusiones y las implicancias de la Ley de sca se inscribieron en dos experiencias de gestión de medios indígenas: Kona Producciones, de Neuquén, y la Radio La Voz Indígena, de Salta. En este artículo nos detendremos en los debates a nivel nacional y su articulación con las trayectorias de luchas indígenas por el derecho a la comunicación en Argentina. 


\section{DISERTACIONES}

ESTUDIOS

\section{Los pueblos indígenas y el Estado argentino}

La 'inclusión' de los pueblos originarios a la nación argentina puede definirse como una historia de sometimiento de los indígenas, signada por el genocidio y la negación de existencia de población originaria en este territorio (Lenton, 2005). Hecho que se materializó en políticas de exterminio físico y cultural que se extendieron hasta entrado el siglo xx (Trinchero, 2009b; Gordillo y Hirsch, 2010).

Durante esos años fue hegemónica la construcción discursiva de los indígenas como un enemigo interno que debía ser exterminado. Construcción que encontró condiciones de decibilidad en una retórica racializada del nosotros nacional y que fue constituyente de los estigmas racistas que porta el Estado argentino desde su formación moderna (Trinchero, 2009b).

Si bien desde el origen del Estado existieron organizaciones de pueblos originarios que lucharon contra el despojo y el sometimiento (Lenton, 2015), desde 1983 -luego de la última dictadura militar (1976-1983) - surgieron nuevas formas de militancia de grupos originarios. Ello marcó el comienzo del período de mayor movilización indígena, en luchas que involucraron principalmente conflictos por la recuperación de tierras de las cuales las comunidades habían sido expulsadas y/o la obtención de títulos de propiedad de estas (Gordillo y Hirsch, 2010).

Desde mediados de los ochenta, una demanda central de esas organizaciones fue la creación de un marco legal para la adquisición de derechos. A partir de esas presiones, y en un contexto internacional que avanzaba hacia el reconocimiento de los derechos de estos pueblos (Doyle, 2015), comenzaron a tener lugar acciones estatales tendientes a un tibio (y a veces contradictorio) reconocimiento de problemáticas de este sector, sobre todo desde el campo jurídico (Mombello, 2002). Nos referimos, por ejemplo, a la sanción de la Ley Nacional 23302 sobre Política Indígena y Apoyo a las Comunidades Aborígenes (1985) y al reconocimiento constitucional de la preexistencia de estos pueblos en la reforma de la Constitución Nacional de 1994.

La Ley 23302 establece el derecho indígena a obtener títulos de propiedad de las tierras que habitan y el reconocimiento de personería jurídica a las comunidades. Además, creó el Instituto Nacional de Asuntos Indígenas (INAI), inspirado en la concepción del Estado como dador de beneficios a los indígenas. Luego, con la reforma constitucional de 1994, el Estado reconoció "la preexistencia étnica y cultural de los pueblos indígenas argentinos”. Y, a partir de ello, su derecho a educación bilingüe y a la propiedad comunitaria de las tierras que tradicionalmente ocupan (C. N., art. 75, inc. 17), entre otras cuestiones.

Al mismo tiempo, estas transformaciones fueron concomitantes con la retirada del Estado en la provisión de coberturas sociales básicas durante los noventa, lo cual operó en sentido inverso al reconocimiento de derechos a los pueblos originarios, pues contribuyó a la pauperización de las poblaciones más vulnerables, entre ellas estos pueblos (Trinchero, 2009a).

En 2003 comenzó un nuevo período político en Argentina, donde se pusieron en cuestión algunas políticas neoliberales hegemónicas desde 1976. El Estado nacional retomó un rol protagónico en el desarrollo económico y social del país, desplegando medidas inclusivas en términos de justicia social. Fue en ese marco que, durante los gobiernos de Néstor Kirchner y de Cristina Fernández de Kirchner se recuperaron algunas de las históricas demandas indígenas. Así, por ejemplo, en 2004 comenzó a funcionar el Consejo de Participación Indígena para incorporar la representación indígena que ordena la Ley 23302 dentro del INAl; en 2006 se creó la Dirección de Pueblos Origi- 


\section{DISERTACIONES}

ESTUDIOS

Comunicación indígena en América Latina

ISSN: 1856-9536

Doi: http://dx.doi.org/10.12804/revistas.urosario.edu.co/disertaciones/a.5479

Volumen 11, Número 2 / Julio-diciembre 2018

Versión PDF para imprimir desde

http://revistas.urosario.edu.co/index.php/disertaciones

narios y Recursos Naturales dentro de la Secretaría de Ambiente y Desarrollo Sustentable de la Nación; ese año también se promulgó la Ley 26160, que suspendió los desalojos de grupos indígenas judicializados y ordenó el relevamiento de tierras de comunidades de todo el país (Briones, 2015).

Simultáneamente, muchas organizaciones siguieron denunciando que actividades como la producción intensiva de soja, la tala de bosques y la minería a gran escala continuaron siendo promovidas, a pesar de estar destruyendo territorios de poblaciones originarias.

Esas contradicciones se inscriben en una deuda que el Estado aún mantiene con esos pueblos: como plantean Roulet y Garrido (2011), pese a ciertos avances en derechos indígenas, Argentina adeuda iniciar una reparación integral en relación con el genocidio cometido contra estos pueblos desde la colonización. Ello involucraría tanto medidas de reparación (restitución, indemnización y rehabilitación, así como garantías de no repetición) como la búsqueda y difusión de la verdad sobre lo vivido por los indígenas, sobre sus situaciones actuales y sobre las responsabilidades del Estado y la sociedad en ello.

Como veremos más adelante, en Argentina la garantía del derecho a la comunicación con respecto a los medios ha comenzado a ser, para algunas organizaciones indígenas, parte de ese proceso de reparación. Y es que los medios, en tanto fuentes de construcción de imaginarios colectivos (Mata, 1999), han ido ocupando un papel preponderante en la consolidación de sentidos hegemónicos sobre la indigeneidad y sobre los procesos de incorporación de los pueblos originarios a las formaciones estatales, generando historicidades simuladas e imágenes estereotipadas en relación con ellos (Bartolomé, 2006).

\section{Lógicas comunicacionales hegemónicas: (in)visibilizaciones y estigmatizaciones indígenas en los medios}

En términos generales, durante todo el siglo xx el Estado nacional reguló los medios en beneficio de intereses del sector con fines de lucro (Mastrini, 2005).

Hubo algunas excepciones a esa tendencia, ya que en distintos períodos históricos tuvieron lugar iniciativas que podrían haber sido un paso en la transformación del carácter privado y excluyente del sistema de medios. Sin embargo, esas iniciativas se vieron, por distintos motivos, truncadas rápidamente. Un ejemplo en ese sentido tuvo lugar en 1953, durante el segundo gobierno de Perón (1952-1955), cuando se sancionó la Ley 14241 de Radiodifusión. En ella se crearon medios gubernamentales, se estableció la necesidad de promover la radiodifusión en el interior del país, se planteó que los medios son "difusores de cultura" y no solo negocios, entre otras cuestiones. Pero en 1955 un golpe de Estado llevó a la presidencia a Lonardi y en 1957 la anterior Ley de Radiodifusión fue trocada por la Ley 15460, que devolvió al Estado su rol subsidiario (Mastrini, 2005). Casi dos décadas después, en 1973, el tercer gobierno peronista estatizó nuevamente los medios. Perón, imbuido del modelo de radiodifusión europeo que había conocido en el exilio, trajo la iniciativa de pasar de un servicio de radiodifusión entendido como 'de interés público' a un 'servicio público' de radiodifusión, financiado principalmente a partir del erario público y que garantice a toda la población el acceso a contenidos plurales, donde el Estado promueva la producción local de contenidos. De todos modos, luego de la muerte de Perón (1974) esta iniciativa fue dejada de lado. Después, con la última dictadura militar no solo se vivieron situaciones de grave censura a medios, periodistas y 


\section{DISERTACIONES}

ESTUDIOS

Comunicación indígena en América Latina

ISSN: 1856-9536

Doi: http://dx.doi.org/10.12804/revistas.urosario.edu.co/disertaciones/a.5479

Volumen 11, Número 2 / Julio-diciembre 2018

Versión PDF para imprimir desde

http://revistas.urosario.edu.co/index.php/disertaciones

población en general, sino que además se sancionó el Decreto-Ley 22285 de Radiodifusión. Entre otras cosas, esta norma establecía que solo podían ser prestadores de servicios de radiodifusión el Estado y los actores con fines de lucro. Ya con el retorno de la democracia, durante el gobierno de Raúl Alfonsín (1983-1989), se plantearon dos tendencias en cuanto a las políticas públicas de comunicación: una privatista, centralista y comercial, representada por el Comité Federal de Radiodifusión (Comfer); y otra que pretendía un régimen con mayor participación del Estado como productor de mensajes mediáticos y gestor de medios masivos de comunicación, con participación de organizaciones intermedias y descentralización de la autoridad de aplicación de la legislación. Esta postura estaba representada por la Secretaría de Información Pública (SIP) y se plasmaba, por ejemplo, en proyectos de ley como el elaborado por el Consejo para la Consolidación de la Democracia (Cocode). Este enfrentamiento de posturas dentro del gobierno implicó una ausencia de acuerdo, lo cual se tradujo en la continuidad (y profundización) del modelo privatista y excluyente (Com, 2005). Y esa tendencia se profundizó durante el gobierno de Carlos Menem (1989-1999), quien desde el primer año de su gestión habilitó mayores posibilidades de concentración de las empresas mediáticas y desfinanció la radio y televisión estatales. ${ }^{2}$ Todo lo cual consolidó un sistema de medios comercial, orientado por la asunción de la comunicación como un negocio y no como un derecho.

Esta histórica tendencia ha tenido impacto en los modos en que los indígenas han sido (in)visibilizados en los medios. En relación con estos pueblos, en general la mirada de los medios masivos mantuvo coherencia con otros discursos hegemónicos que primero buscaron instalar la construcción del indígena como un enemigo interno y luego su relegamiento a un pasado folclórico, salvo casos en que aparecieron como menores de edad, como indígenas falsos o sujetos violentos (Giordano, 2004; Delrio, 2010; Valko, 2007; Lenton, 2005).

Desde mediados de los noventa, cuando se incrementaron las movilizaciones de pueblos originarios por la tierra, se generó una reacción por parte de las empresas mediáticas, intentando deslegitimar estas luchas: tergiversando demandas, invisibilizando a los pueblos y sus necesidades, o poniendo en duda su carácter preexistente en el territorio (Trentini et al., 2010; Radovich, 2014; Lizondo, 2015).

En la última década estas modalidades de presencia/ausencia de los indígenas en los discursos mediáticos hegemónicos siguieron vigentes: la presencia de pueblos originarios es escasa, rozando la invisibilización casi total (Inadi, 2005, p. 3), y "sólo aparecen en los medios cuando hay algún caso muy resonante, casi siempre ligado a un conflicto de tierras con terratenientes o empresas que pretenden desalojarlos, sin que se contextualice con sus derechos reconocidos constitucionalmente" (Inadi, 2005, p. 281).

Ello afecta sus posibilidades de ejercicio del derecho a la comunicación y constituye un obstáculo a los procesos de lucha indígena. Tal como planteó un comunicador kolla,

En el Coyamarca de la provincia de Salta tenemos problemas con los distintos pueblos, porque en Salta los medios masivos son de 2 o 3 personas que bajan información como lo que nos bajan aquí desde Buenos Aires. [...] Todos conocen el amparo que se pidió para frenar los desmontes: nos hemos juntado tobas, wichí,

2 En Argentina, las cuatro principales empresas de medios controlan más del $85 \%$ del mercado, con lo cual, afirman Becerra y Mastrini (2012, p. 1), se superan con creces los estándares internacionales aceptables: "De acuerdo con Albarran y Dimmick (1996), se considera que la concentración es alta al superar un promedio del $50 \%$ del control de un mercado por parte de los cuatro primeros operadores y un $75 \%$ por los ocho primeros operadores". 


\section{DISERTACIONES}

ESTUDIOS

Comunicación indigena en América Latina

ISSN: 1856-9536

Doi: http://dx.doi.org/10.12804/revistas.urosario.edu.co/disertaciones/a.5479

Volumen 11, Número 2 / Julio-diciembre 2018

Versión PDF para imprimir desde

http://revistas.urosario.edu.co/index.php/disertaciones

kollas, para venir a Buenos Aires para que ese amparo se logre. Hoy la provincia sigue insistiendo, los grandes terratenientes siguen insistiendo para el desmonte. Los grandes poderes de la comunicación no sacan a la luz eso. [...] Nosotros, los que venimos de la Puna, estamos invisibilizados también por la distancia.

Estos límites al derecho a la comunicación fundamentaron los esfuerzos de comunidades y organizaciones por crear medios propios y constituirse en interlocutores legítimos en la definición de las reglas que organizan el sistema de medios en Argentina.

\section{Trayectorias de las experiencias de comunicación indígena en Argentina}

Tal como ocurrió en otros países de Latinoamérica, durante la década de los setenta surgieron en Argentina experiencias de comunicación popular que promovieron la participación indígena en medios de comunicación (Doyle, 2015).

Fue el caso, por ejemplo, del Instituto de Cultura Popular (Incupo), una entidad no gubernamental fundada en 1969 que "nació bajo la inspiración del modelo de las llamadas instituciones de educación radiofónica que por esa época se extendían en América Latina” (De Dios y Vigil, 1985, p. 56). Desde su creación, el Incupo trabajó en el norte argentino, con grupos qom, wichí, pilagá y rnocoví, campesinos y pobladores de barrios o villas, con el objetivo de "colaborar con los sectores populares más desposeídos [...] en la gestación y el fortalecimiento de sus organizaciones, en la apropiación y profundización del saber y en la experiencia histórica de protagonismo" (De Dios y Vigil, 1985, p. 56). Entre otras actividades, esta institución desarrolló “medios e instrumentos de comunicación y educación popular: programas radiales para espacios alquilados a la red comercial; cartillas y folletos con temas específicos; un periódico de publicación mensual; audiovisuales; cassettes..." (De Dios y Vigil, 1985, p. 56).

También en Neuquén surgieron experiencias de comunicación popular con participación de mapuches, de la mano de la iniciativa del obispo Jaime de Nevares. En 1979 se creó el Servicio Pastoral para la Comunicación del Obispado de Neuquén, que desde 1981 editó la Revista Comunidad y desde 1983 produjo materiales radiofónicos que eran trasmitidos en diferentes radios de la provincia. En esas producciones aparecieron las voces de organizaciones y autoridades del pueblo mapuche. Nos referimos, por ejemplo, a la 'colección' que se denominó "Memoria de la Tierra”, elaborada durante los encuentros zonales de capacitación de líderes comunitarios (1989 y 1991), y que fueron organizados por el Servicio Pastoral para la Comunicación con la participación de la Asociación Mapuche Urbana Nehuén Mapu, el Centro Mapuche de Junín de los Andes y la Asociación de Cooperativas Comunidades Mapuche Neuquinas (Serpac, s. a.). La colección recopilaba relatos de ancianos y autoridades de 24 comunidades mapuches, referidos a la invasión militar de su territorio, la odisea de los grupos y los problemas sufridos en la posesión de sus tierras. Esa recopilación fue emitida por Radio Comunidad Enrique Angelelli (de la ciudad de Neuquén) y otras emisoras de la Patagonia.

Durante la década de los noventa muchos miembros de pueblos originarios, en distintos puntos del país, se insertaron a trabajar en medios de comunicación que se autodefinían populares, alternativos o comunitarios

3 Exposición en conferencia de prensa ofrecida por el ENOTPO luego de que el Proyecto de Ley de scA obtuviera media sanción en la Cámara de Diputados de la Nación. 18 de septiembre de 2009, Buenos Aires. Registro de campo. 


\section{DISERTACIONES}

ESTUDIOS

Comunicación indigena en América Latina

ISSN: 1856-9536

Doi: http://dx.doi.org/10.12804/revistas.urosario.edu.co/disertaciones/a.5479

Volumen 11, Número 2 / Julio-diciembre 2018

Versión PDF para imprimir desde

http://revistas.urosario.edu.co/index.php/disertaciones

(Kejval, 2013). Tal como explicaba un comunicador mapuche, " "[...] en el sur, en Chaco, en Jujuy [...] ya había comunicadores que venían trabajando dentro del esquema de las radios comunitarias [...] Nos conocíamos por diferentes encuentros de capacitación que se habían hecho, a través de las radios comunitarias nos conocimos con varios [...]".

Radio Alas en provincia de Río Negro, Radio Pocahullo en provincia de Neuquén o las producciones del Incupo en el norte argentino fueron algunos de los ámbitos de inserción y formación de miembros de pueblos originarios.

En sintonía con lo ocurrido en el resto de América Latina (Doyle, 2013), y como parte de un proceso de revalorización y visibilización de las identidades étnicas, desde fines de los noventa y, sobre todo, desde 2000 comenzaron a multiplicarse medios autodefinidos indígenas, medios en los cuales la explicitación de la indigeneidad empezó a aparecer como un elemento clave y distintivo respecto de otras experiencias de comunicación sin fines de lucro. En ese marco, a partir de inicios de la década de 2000 se organizaron encuentros de comunicadores(as) de pueblos originarios y se empezaron a gestar redes que pusieron en contacto a medios y comunicadores(as) indígenas de distintas regiones. Muchos de esos espacios tuvieron acompañamiento (particularmente para la formación en producción de medios) de carreras de comunicación social de universidades nacionales, de medios comunitarios o de ong y fundaciones.

Por ejemplo, en 2002 tres organizaciones del norte argentino (la comisión zonal de tierra Cacique Taigoyic, el Equipo de Tierra Qom del Departamento Bermejo y la Federación Pilagá de Formosa), con el acompañamiento del Incupo, impulsaron capacitaciones en producción radiofónica para jóvenes de pueblos originarios, a partir de las cuales nació la Red de Comunicación Indígena.

En 2001, en el marco de las discusiones sobre la inclusión de la temática indígena en el censo nacional de ese año, se consolidó en Río Negro una red de jóvenes mapuches que tomó la forma de una campaña denominada 'Campaña de Autoafirmación Mapuche Wefkvletuyiñ (estamos resurgiendo)', que incluye un grupo de trabajo en comunicación (Kropff, 2004).

En 2003 se creó en Santiago del Estero la primera radio campesino-indígena del Movimiento Campesino de Santiago del Estero. A ella sucedieron otras cinco emisoras ubicadas en distintas localidades de esa provincia. Para la puesta en funcionamiento de estas radios, el Movimiento contó con el apoyo de la radio comunitaria La Tribu, de Buenos Aires, y con financiamiento de ong extranjeras (Desalvo, 2014).

En el año 2000, jóvenes de la Confederación Mapuche de Neuquén comenzaron a editar una revista, programas de radio y documentales (Doyle, 2017). A su vez, a partir del vínculo con la fm Pocahullo, de Neuquén, y con el portal informativo mapuche de Chile, Mapuexpress, organizaron tres encuentros de comunicadores mapuches entre 2004 y 2006 (Grillo, 2009). De esos encuentros surgió la Red de Emisoras Interculturales de Neuquén.

En Salta, desde 2002, un grupo de mujeres y caciques de distintos pueblos emitió el programa La Voz Indígena en Radio Nacional Tartagal (Lizondo, 2015; Doyle, 2017).

En Cuesta del Ternero, provincia de Río Negro, y en El Hoyo, Chubut, dos comunidades mapuches trabajaron desde inicios de 2000 con cabinas radiofónicas para difundir noticias (Yanniello, 2014).

4 Entrevista: Buenos Aires, 05/2015. 


\section{DISERTACIONES}

ESTUDIOS

Comunicación indígena en América Latina

ISSN: 1856-9536

Doi: http://dx.doi.org/10.12804/revistas.urosario.edu.co/disertaciones/a.5479

Volumen 11, Número 2 / Julio-diciembre 2018

Versión PDF para imprimir desde

http://revistas.urosario.edu.co/index.php/disertaciones

Sin embargo, como señalamos, ello ocurría en un contexto de profunda adversidad para las experiencias de comunicación sin fines de lucro, con un marco legal que las condenaba a la ilegalidad y un Estado nacional que actuaba desde la concepción de la comunicación como un negocio.

\section{Los pueblos indígenas en la Ley de sca: antecedentes y debates}

Desde 1999 y hasta 2001, la entonces autoridad estatal de regulación de la radio y la televisión, el Comité Federal de Radiodifusión (Comfer), tuvo una gestión que buscó abrir una fisura en el sistema de medios de Argentina para permitir el ingreso, aunque sea marginal, de actores sin fines de lucro. ${ }^{5}$ Entre otras cuestiones, durante ese período comenzó a implementarse el programa Radios en Escuelas Rurales y de Frontera, a partir del convenio entre el Comfer y el Ministerio de Educación, Ciencia y Tecnología de la Nación. ${ }^{6}$ Como parte de ese convenio, en 2001 el Comfer autorizó por primera vez la transmisión a una radio con programación bilingüe (guaraní y castellano): la radio escolar FM Cheru Roque, en Salta.

Y a inicios de 2004, en el Comfer se creó el programa Radios en Comunidades y Asociaciones Indígenas, producto de un convenio entre el Comfer y el INAI. ${ }^{8}$ En el marco de ese convenio, que buscaba apoyar la instalación de emisoras indígenas, se pusieron en funcionamiento nueve radios: ${ }^{9}$ cuatro del pueblo mapuche, una del pueblo diaguita calchaquí, dos del pueblo kolla y dos del pueblo qom. ${ }^{10}$

A su vez, en 2004 tuvo lugar un acontecimiento que fue clave en el proceso de creación de una nueva ley que regulara los servicios de comunicación audiovisual, reemplazando a la 22285 sancionada durante la dictadura. Ese año se conformó la Coalición por una Radiodifusión Democrática, una entidad supraorganizacional que integró a medios comunitarios, carreras de comunicación, académicos, diversos sindicatos y organizaciones de distinto tipo, y cuyo objetivo fue impulsar la lucha por una nueva ley de radiodifusión. Paulatinamente, la Coalición se conformó como el espacio que nucleó a múltiples sectores que luchaban por la democratización del sistema de medios. Y se fue legitimando como una voz que buscó instalar públicamente que el derecho a la comunicación es un derecho humano, construyendo consenso en torno a "una redefinición de los medios como instituciones públicas pasibles de ser reguladas, orientadas y organizadas bajo los fundamentos de la institucionalidad democrática: igualdad y libertad" (Córdoba, 2013, p. 183).

5 Durante esos años fue interventor del Comfer el periodista y abogado Gustavo López, quien integró a su equipo de trabajo a gente vinculada al sector de medios comunitarios.

6 Resolución 705-Comfer/00.

7 Resolución 576-Comfer/01.

8 Resolución 403-Comfer/04.

9 Autoridad Federal de Servicios de Comunicación Audiovisual. (2011). Listado de autorizaciones a comunidades indígenas. Inédito.

10 Durante este período también surgieron, por fuera de ese convenio, otras emisoras indígenas. Algunas adquirieron autorización del AFSCA luego de la sanción de la Ley de SCA y otras aún no han recibido autorización. 


\section{DISERTACIONES}

ESTUDIOS

Comunicación indigena en América Latina

ISSN: 1856-9536

Doi: http://dx.doi.org/10.12804/revistas.urosario.edu.co/disertaciones/a.5479

Volumen 11, Número 2 / Julio-diciembre 2018

Versión PDF para imprimir desde

http://revistas.urosario.edu.co/index.php/disertaciones

Al ir instalándose esta perspectiva, surgieron en su interior otros debates. Uno de ellos tuvo que ver con la existencia o no de una pluralidad de modos de asumir y demandar la garantía de ese derecho humano. Y, de la mano con ello, sobre la posibilidad o no de que en su reconocimiento jurídico ese derecho sea, efectivamente, universal.

Nos referimos al hecho de que, desde 2004, algunos(as) comunicadores(as) indígenas participaban en reuniones de la Coalición y seguían las discusiones que allí se daban, pero no se sentían plenamente incluidos en ellas. Así lo explicaban una comunicadora y un comunicador que integraron el ENOTPO: “[...] nosotros no fuimos contemplados: ni, por supuesto, desde los organismos del Estado que estaban trabajando para la nueva ley, ni tampoco desde los sectores sociales, desde la Coalición ni desde ningún ámbito. 0 sea, una cosa es invitarte y otra cosa es estar incluido o contemplado en una ley. Nos habían invitado a reuniones, espacios, y otra cosa es tener en cuenta que tenemos que ser reconocidos". ${ }^{11}$

En 2008 estuvimos en una reunión varios de estos comunicadores [indígenas] en Córdoba, creo que fue en Embalse de Río III. Ahí se hizo un encuentro del Foro Argentino de Radios Comunitarias donde varios de los que veníamos trabajando nos conocíamos y nos encontramos ahí [alude a comunicadores indígenas de distintos puntos del país]. A esa reunión asistió Luis Lázzaro que en ese momento era el coordinador general del Comfer [...]. Puntualmente le planteamos que debía haber un reconocimiento más explícito de las comunidades y de los pueblos indígenas de Argentina en caso de sancionarse la ley. Se dio ahí una discusión con el presidente de uno de estos foros, que obviamente no quedó en nada esa y tomó mucha más fuerza de que se iba a producir la modificación de la Ley 22285 y de que íbamos a tener que, digamos, generar un espacio o nos íbamos a tener que generar el espacio propiamente. ${ }^{12}$

En el año 2008 se comenzó a vislumbrar en el horizonte la posibilidad de que el Poder Ejecutivo Nacional (PEN) elaborara una nueva ley. Y, efectivamente, en marzo de 2009 la entonces presidenta de la Nación, Cristina Fernández de Kirchner, presentó la propuesta de Proyecto de Ley de scA: un proyecto que se fundamentaba en los postulados de la Coalición, y que regularía los servicios de radiodifusión sonora y televisiva tradicionales, la actividad de la televisión a demanda, las productoras de contenidos audiovisuales y la publicidad de esos medios.

En ese momento, Fernández de Kirchner también anunció el inicio de un período de discusión pública, a nivel nacional, de dicha propuesta: a través de 23 foros, los ciudadanos realizaron sugerencias al documento que sería enviado al poder legislativo. Allí (y en otras conferencias organizadas por los mismos indígenas) también participaron y debatieron muchos miembros de pueblos originarios (Guzmán, 2011).

Según el Proyecto de Ley del Pen, estos pueblos constituirían parte del sector privado sin fines de lucro. Esta modalidad de inclusión motivó que, inmediatamente después del anuncio de dicha propuesta, un grupo de aproximadamente 30 comunicadores de pueblos originarios de distintos puntos del país comenzara a trabajar en un documento que se tituló "Propuesta de inclusión del derecho a la comunicación con identidad de organizaciones de los pueblos originarios en el anteproyecto de ley de servicios de comunicación audiovisual". ${ }^{13}$

Una demanda central en ese documento fue que el proyecto no incluyera a los indígenas dentro del sector privado sin fines de lucro, sino que los reconociera como sujetos de derecho público no estatal. De esa propuesta

11 Entrevista a comunicadora mapuche: Córdoba, 11/2011.

12 Entrevista a comunicador mapuche: Buenos Aires, 05/2015.

13 A la cual suscribieron 23 organizaciones indígenas de todo el país. 


\section{DISERTACIONES}

ESTUDIOS

Comunicación indígena en América Latina

ISSN: 1856-9536

Doi: http://dx.doi.org/10.12804/revistas.urosario.edu.co/disertaciones/a.5479

Volumen 11, Número 2 / Julio-diciembre 2018

Versión PDF para imprimir desde

http://revistas.urosario.edu.co/index.php/disertaciones

se desprendían, a su vez, otras demandas: que pudieran ser titulares de autorizaciones (y no de licencias) para la explotación de sca y que estas autorizaciones se otorgaran de manera directa a la organización que lo demandase; que el Estado nacional se comprometiese a destinar fondos para financiar los medios indígenas; que garantizase la promoción de las culturas originarias en medios estatales y privados; y que los contenidos por difundir fueran producidos por cada pueblo; finalmente, se exigía que el proyecto contemplara la participación de representantes indígenas en los órganos de aplicación de la futura ley.

Esta demanda de reconocimiento de los pueblos originarios como sujetos diferentes respecto del sector sin fines de lucro -y particularmente la de ser reconocidos como sujetos de derecho público- tuvo fundamentos de distinto orden.

Por un lado, plantearon quienes elaboraron la propuesta, la ley no podía desconocer la situación jurídica y política particular de los indígenas en Argentina, ya que el reconocimiento constitucional de su preexistencia posiciona a estos pueblos en paridad a toda entidad pública (Nussbaumer, 2014). En virtud de ello, no debían ser incluidos en la ley bajo la categoría de minorías "porque no es legítimo comprender en un mismo concepto situaciones como las de minorías migrantes con pueblos originarios del país, incorporados contra nuestra voluntad al dominio de los Estados modernos que nos fueron impuestos". ${ }^{14}$ La homologación con una asociación civil privada colocaría en el Estado el poder de otorgar derecho de uso sobre el espectro radioeléctrico, mientras que el reconocimiento de la preexistencia indígena, y, por lo tanto, su carácter de sujetos de derecho público no estatal, promovería el acceso directo a ello.

En relación con eso, quienes elaboraron la "Propuesta de inclusión del derecho a la comunicación con identidad..." plantearon que el derecho al acceso libre al espectro radioeléctrico es parte del derecho indígena a la posesión comunitaria de las tierras que tradicionalmente ocupan, dado que el espectro radioeléctrico es parte de esas tierras. En ese sentido, la lucha por el derecho al uso del espectro es también la lucha por la tierra:

[...] nosotros no consideramos que nuestro territorio es solamente la superficie de todo lo que se ve, nuestro territorio va desde el centro de la Tierra hasta más allá del infinito. Todas las culturas originarias del Abya Yala tenemos esta cosmovisión. Consideramos así nuestro territorio. Pero no decimos que somos dueños de él sino que es nuestro porque somos parte de él, como lo es una piedra, un ave, una planta. Por eso hoy vemos que nuestros territorios están siendo invadidos por las señales de radio, de celulares, de televisión, y muchas veces no se consulta eso con los pueblos que vivimos ahí (comunicador kolla). ${ }^{15}$

También se plantearon otros argumentos de orden político-cultural. Actualmente los medios son espacios centrales para el ejercicio del derecho a la verdad, que es parte del derecho a la comunicación: ${ }^{16}$ es decir, el derecho de los pueblos originarios, y de la sociedad toda, a que se conozca lo que los indígenas tienen para narrar

14 (2009). Propuesta de inclusión del derecho a la comunicación con identidad de organizaciones de los pueblos originarios en el anteproyecto de Ley de Servicios de Comunicación Audiovisual. Documento elaborado en el Encuentro Nacional de Organizaciones de Pueblos Originarios, Buenos Aires. Mimeo.

15 Exposición en conferencia de prensa del ENOTPO. 18 de septiembre de 2009, Buenos Aires. Registro de campo.

16 En los últimos años, la unEsco comenzó a plantear la relación entre derecho a la información y derecho a la verdad en los casos de violaciones de derechos humanos: en estos casos, afirman Loreti y Lozano (2014), el acceso a la información resulta instrumental al derecho de las víctimas, sus familiares y de la sociedad en su conjunto a conocer lo ocurrido sobre las atrocidades cometidas en el pasado y hasta en el presente. 


\section{DISERTACIONES}

ESTUDIOS

Comunicación indígena en América Latina

ISSN: 1856-9536

Doi: http://dx.doi.org/10.12804/revistas.urosario.edu.co/disertaciones/a.5479

Volumen 11, Número 2 / Julio-diciembre 2018

Versión PDF para imprimir desde

http://revistas.urosario.edu.co/index.php/disertaciones

sobre la historia de su inclusión a la nación y sobre sus actuales condiciones de vida y sus luchas. En ese sentido, revertir la invisibilización en los medios es un paso fundamental para ampliar las posibilidades de ejercicio de distintos derechos:

[...] la Argentina tiene una deuda histórica con los pueblos originarios y estamos invisibilizados desde siempre. Y nos damos cuenta de que nunca estuvimos en la agenda de ningún gobierno de turno ni lo vamos a estar. Por esas razones hemos generado este trabajo desde las bases para participar en las políticas públicas desde nuestra cosmovisión, haciendo valer los derechos que han logrado algunos hermanos en el 94 y el Convenio 169 [...] Salta es una provincia feudal, en la cual los medios masivos que hay no nos hacen visibles ni lo van a hacer. Por eso nosotros apoyamos y exigimos la participación plena. Y esta ley de comunicación a nosotros nos sirve para tener nuestros propios medios y poder contar las situaciones que aquí se denuncian, la realidad que pasa en nuestras comunidades (comunicador kolla). ${ }^{17}$

Por otro lado, al mismo tiempo que se denunciaba el silenciamiento por parte de medios comerciales, algunos indígenas también cuestionaban el histórico papel de voceros que algunos medios comunitarios asumieron respecto de los pueblos originarios. Explicaban que, en cierta medida, la demanda de ser reconocidos como pueblos originarios dentro de una nueva ley se fue construyendo en sus propias trayectorias de participación en medios comunitarios: trayectorias atravesadas, en general, por desigualdades en lo que respecta a toma de decisiones sobre la gestión de esos medios. En ese sentido, un comunicador del ENOTPO decía: ${ }^{18}$

Esto también está ligado a que muchos de nosotros en la década de los noventa colaboramos en la creación de medios de comunicación, de muchos medios de comunicación comunitaria en donde, digamos, era como que nosotros pedíamos el micrófono prestado para poder decir lo que teníamos que decir.

¿Nosotros decís los indígenas?

Los indígenas [...] habían muchos de los chicos que criticaban esto, que decían "las radios comunitarias: la voz de los sin voz". Esa palabrita, esa oración que muchas veces las radios comunitarias, que muchos comunicadores en la radio decían [...] dentro de lo que era el grupo de trabajo de los pibes que estábamos trabajando la ley de medios nos sonaba a paternalismo, a una cuestión que estaba bastante lejos de lo que nosotros queríamos. ${ }^{19}$

Este derecho, explican, genera en el Estado una obligación de investigar y de preservar la memoria colectiva e impedir la repetición de crímenes contra la humanidad.

17 Exposición en conferencia de prensa del ENOTPO. 18 de septiembre de 2009, Buenos Aires. Registro de campo.

18 Entrevista: Buenos Aires, 05/2015.

19 Esto no quita el reconocimiento que los indígenas hacen de los medios comunitarios como ámbitos en los cuales muchos de ellos se formaron: "[...] muchos de los comunicadores indígenas que conformamos el Encuentro de Organizaciones hemos sido parte de los medios que se fueron levantando en la década de los noventa conocidos como radios comunitarias [...]. Ese trabajo, esa visibilización de los medios de comunicación ha hecho que nos despertemos, por decirlo de alguna manera, y eso nos ha llevado hasta el proceso de generar una propuesta de comunicación, de inclusión del derecho a la comunicación con identidad [...]" (comunicador mapuche en conferencia de prensa del ENOTPO. Registro de campo). 


\section{DISERTACIONES}

ESTUDIOS

Comunicación indigena en América Latina

ISSN: 1856-9536

Doi: http://dx.doi.org/10.12804/revistas.urosario.edu.co/disertaciones/a.5479

Volumen 11, Número 2 / Julio-diciembre 2018

Versión PDF para imprimir desde

http://revistas.urosario.edu.co/index.php/disertaciones

Por ello, un sistema de medios intercultural sería aquel que reconociera a los medios que administra un pueblo originario como medios indígenas, medios que "parte[n] desde una identidad ancestral y una cosmovisión milenaria" (comunicador mapuche). ${ }^{20}$ Esos medios

[...] son administrados por organizaciones de los pueblos originarios y tienen como objetivo la difusión

y la preservación de los derechos de los pueblos indígenas preexistentes a la creación del Estado: idio-

mas, instituciones propias, cosmovisión, educación, ceremonias... Por tanto, el concepto de comunitario

popular no alcanza a contener y limita la comunicación indígena porque desconoce nuestro carácter jurí-

dico y político de pueblo originario con identidad propia [...]. ${ }^{21}$

Desde este planteo, "cuando los medios de comunicación indígenas estén en igualdad de derechos frente a los medios privados, estatales y comunitarios en el espectro radioeléctrico, podremos hablar de interculturalidad en la comunicación. Porque de esa manera se contribuirá a fortalecer la democracia argentina" (comunicador mapuche). ${ }^{22}$

Esta definición de un sistema de medios intercultural se inscribía, a su vez, en una concepción de la interculturalidad entendida como la existencia, en una sociedad, de posibilidades de expresión de todas las culturas e identidades. Así, la interculturalidad no es una concesión desde los grupos dominantes para grupos subordinados, sino que se debe promover el aprendizaje y respeto mutuos, tanto al coincidir como al disentir. Y se vincula, a su vez, con la importancia de resolver dos tipos de discriminación que sufren los pueblos indígenas: exclusión económica y política e irrespeto valorativo. Esta concepción de interculturalidad es reivindicada por organizaciones mapuches en la patagónica provincia de Neuquén (Briones et al., 2006), a las cuales pertenecían varios jóvenes que participaron en la elaboración de la "Propuesta de inclusión del derecho a la comunicación con identidad...".

\section{Participación indígena en el sistema de medios a partir de la Ley de SCA: transformaciones y pendientes}

Finalmente, el 9 de octubre de 2009 se sancionó la Ley Nacional 26522 de sca. Esta ley efectivamente incluyó la propuesta presentada por los indígenas: reconoce los idiomas de los pueblos originarios (art. 9०); establece la participación de representantes de estos pueblos en órganos de aplicación de la ley (art. 16, inc. i; art. 124, inc. g); los define como sujetos de derecho público no estatal (arts. 37, 89, 151) y reserva una frecuencia de am, una de fm y una de televisión para los pueblos originarios en las localidades donde estén asentados; obliga al Estado a destinar fondos provenientes del pago de gravámenes de los licenciatarios de sca para apoyar los medios indígenas (art. 97, inc. f); establece que el INAl debe asignar fondos para tal fin; y garantiza exenciones impositivas (art. 98, inc. e).

20 Ponencia presentada en Cámara de Diputados de la Nación, en la audiencia pública desarrollada entre el 8 y 11 de septiembre de 2009 para el debate del Proyecto de Ley de sca. Recuperado de http://www1.hcdn. gov.ar/radiodifusion/pdf/ponencias/ponencias.pdf

21 Documento en Power Point elaborado por comunicadores indígenas que redactaron la "Propuesta de inclusión del derecho a la comunicación con identidad...”. Registro de campo.

22 Ponencia presentada en Cámara de Diputados de la Nación, en la audiencia pública desarrollada entre el 8 y 11 de septiembre de 2009 para el debate del Proyecto de Ley de sca. Recuperado de http://www1.hcdn. gov.ar/radiodifusion/pdf/ponencias/ponencias.pdf 


\section{DISERTACIONES}

ESTUDIOS

Comunicación indigena en América Latina

ISSN: 1856-9536

Doi: http://dx.doi.org/10.12804/revistas.urosario.edu.co/disertaciones/a.5479

Volumen 11, Número 2 / Julio-diciembre 2018

Versión PDF para imprimir desde

http://revistas.urosario.edu.co/index.php/disertaciones

A partir de ese reconocimiento político y jurídico, comenzó un proceso de transformaciones en las posibilidades de acceso y participación indígena en el sistema de medios de Argentina.

Tal como explica Rossi (2006), dos indicadores con respecto al nivel de democratización de los sistemas de medios son las posibilidades de acceso y participación social en ellos. Aquí nos centraremos en las transformaciones respecto a posibilidades de participación indígena, dado que es en relación con ello que se implementaron políticas específicas para este sector de la población. Pero nos interesa mencionar dos cuestiones respecto de las transformaciones en el acceso de los indígenas al sistema de medios, ambas vinculadas con políticas públicas nacionales que persiguieron la ampliación del acceso universal.

El primer nivel del acceso está dado por las posibilidades de elección por parte del público, esto es, por la constitución de una trama de soportes masivos que permita que los habitantes puedan elegir entre diversas formas de comunicación (Rossi, 2006). Si bien no hay datos estadísticos respecto a cobertura de medios en población originaria, podemos postular que las políticas - a las que luego haremos referencia- de creación de medios en comunidades indígenas, junto con medidas como la distribución de decodificadores de televisión digital abierta a población que recibe jubilaciones mínimas, asignación universal por hijo o pensiones no contributivas, pueden haber incrementado las posibilidades de acceso en población indígena.

El segundo nivel de acceso es la retroacción, la posibilidad de interacción entre productores y receptores de los programas (Rossi, 2006). En cuanto a este nivel, cobró centralidad la Defensoría del Público de Servicios de Comunicación Audiovisual, organismo creado por la Ley de sca en el cual los públicos de radio y televisión pueden manifestar necesidades, quejas, sugerencias sobre los contenidos que se transmiten. Tal como informa la Defensoría (2015), desde su creación se receptaron más de 5000 presentaciones por parte de los públicos (además de las presentaciones que se realizaron en las audiencias públicas organizadas por dicha entidad). De esas presentaciones, el $79 \%$ corresponde a reclamos y/o consultas vinculadas a cuestiones de acceso (interferencia, accesibilidad, cumplimiento de la grilla) y el $27 \%$ restante consiste en reclamos y denuncias sobre representaciones mediáticas (Defensoría, 2015). Entre esas denuncias, el 2,3\% corresponde a reclamos sobre formas lesivas de los medios masivos para con los pueblos originarios. Luego de receptar las presentaciones, la Defensoría las evalúa y, si corresponde, actúa mediando entre el público y el medio en cuestión.

En el caso de denuncias presentadas por pueblos originarios, un ejemplo de intervención de la Defensoría que ilustra el modo en que este organismo comenzó a abrir arenas de interlocución entre los medios y los indígenas fue su actuación a partir de denuncias presentadas por la Confederación Mapuche de Neuquén contra el programa radial Contrafuego, de am 500 Radio La Primera (provincia de Neuquén). En su exposición, la Confederación denunció trato discriminatorio por parte del programa hacia el pueblo mapuche. La Defensoría analizó esa denuncia y los audios del programa y encontró discriminación, injurias, estereotipos negativos, etc. En virtud de ello, estableció diálogo con la emisora y dictó, para sus periodistas, talleres sobre comunicación e identidades sociales, no discriminación y tratos igualitarios..$^{23}$

Respecto de la participación en el sistema de medios, esta puede darse en tres niveles. El primero refiere a la posibilidad de que el público, grupos o individuos, produzcan programas, disponiendo de espacios de programación, ayuda profesional y recursos técnicos. También puede identificarse como participación de primer grado a

23 Resolución DPSCA 140/2014. 


\section{DISERTACIONES}

ESTUDIOS

Comunicación indígena en América Latina

ISSN: 1856-9536

Doi: http://dx.doi.org/10.12804/revistas.urosario.edu.co/disertaciones/a.5479

Volumen 11, Número 2 / Julio-diciembre 2018

Versión PDF para imprimir desde

http://revistas.urosario.edu.co/index.php/disertaciones

las experiencias de acceso comunitario que habilitan la expresión de grupos con escasa representación en medios tradicionales (Rossi, 2006). Para el caso de los SCA, cobra centralidad en este punto la democratización del acceso a frecuencias de radiodifusión para todos los actores sociales. Pero también los beneficios impositivos otorgados por el Estado, apoyo a compra de equipamiento, capacitación de recursos humanos.

En relación con pueblos indígenas, desde la sanción de la Ley de SCA el AFSCA otorgó autorizaciones de uso del espectro a emisoras de radio que ya venían funcionando y a comunidades que aún no contaban con sus medios pero estaban interesadas en tenerlos. Hasta diciembre de 2015 se otorgaron 55 autorizaciones (54 radios fm y un canal de tv)..$^{24}$

En la creación y fortalecimiento de esas emisoras adquirieron centralidad los Fondos de Fomento Concursable (Fomeca) del AfsCA. Este financiamiento, destinado al sector sin fines de lucro y a pueblos originarios, se implementó desde 2013 y asignó fondos en distintas líneas: producción de contenidos audiovisuales para radio o televisión, compra o mejora de equipamiento para radio o televisión y mejora de aspectos económicos, legales y sociales de la gestión de medios audiovisuales. A partir de 2014 se implementó una línea de financiamiento denominada "Comunicación con identidad", destinada a pueblos originarios, aunque estos podían presentarse también en las otras líneas. Desde 2013 se otorgaron alrededor de 65 Fomeca a emisoras de pueblos originarios. También resultaron ganadoras de Fomeca algunas comunidades que no poseían emisoras propias, con el fin de que pudieran generar productos que se transmitieran por otros medios. ${ }^{25}$

A su vez, como parte de esta política de fortalecimiento de emisoras indígenas, se dictaron capacitaciones en producción de contenidos audiovisuales para comunicadores(as) de esos pueblos. Estas capacitaciones fueron llevadas adelante por el AFSCA, por el área de comunicación del InA y por la Defensoría del Público de Servicios de Comunicación Audiovisual.

Simultáneamente, desde otras áreas del PEN también se desarrollaron diversas líneas de acción. Por ejemplo, el apoyo de la Secretaría de Agricultura Familiar de la Nación a medios rurales (Müller, Elbirt y Leal, 2015), o la difusión de producciones audiovisuales sobre temática indígena a través de la Semana de Cine de los Pueblos Indígenas, que organizaba y financiaba el Ministerio de Cultura de la Nación en coordinación con el INAl.

Además de estos avances, también se reconocían cuestiones pendientes en lo relativo a este primer nivel de participación: por ejemplo, la apertura de posibilidades de participación indígena en los medios públicos estatales ${ }^{26}$ y la asignación de recursos del INAI a los SCA de pueblos indígenas (establecida por el artículo 151 de la Ley de SCA). ${ }^{27}$

En su segundo nivel, la participación refiere a la posibilidad de intervención de la sociedad civil en la toma de decisiones respecto de cuestiones puntuales del funcionamiento del sistema de medios. En relación con ello, las modalidades de participación pueden ir desde audiencias públicas hasta la participación en los consejos asesores de los entes públicos, pudiendo tomar parte en decisiones sobre funcionamiento del sistema de medios (Rossi, 2006).

24 Listado de autorizaciones a comunidades indígenas, op. cit.

25 http://afsca.gob.ar/experiencias-anteriores/

26 En el I Parlamento Internacional sobre Comunicación Indígena, que tuvo lugar en Buenos Aires en noviembre de 2012, se planteó el interés de las comunidades en participar de los medios públicos estatales por su gran alcance geográfico, incluso en zonas rurales (registro de campo). Hasta diciembre de 2015, el único paso en ese sentido fue la inclusión de un comunicador mapuche en Télam, agencia oficial de noticias.

27 Entrevista a comunicador indígena del EnotPo: Buenos Aires, 05/2015. 


\section{DISERTACIONES}

ESTUDIOS

Comunicación indígena en América Latina

ISSN: 1856-9536

Doi: http://dx.doi.org/10.12804/revistas.urosario.edu.co/disertaciones/a.5479

Volumen 11, Número 2 / Julio-diciembre 2018

Versión PDF para imprimir desde

http://revistas.urosario.edu.co/index.php/disertaciones

En el caso de los pueblos indígenas, a partir de la sanción de la ley se institucionalizó la presencia de un representante en el Consejo Federal de Comunicación Audiovisual, órgano cuyas funciones eran, entre otras, elaborary asesorar al directorio del AFsca en el diseño de la política pública de radiodifusión.

Finalmente, el tercer nivel de participación remite a las posibilidades de participación de la población en la planificación general del sistema de medios. En el caso de la elaboración y sanción de la Ley de sca en Argentina, como señalamos, hubo instancias de participación de la ciudadanía para la redacción del proyecto de ley. Y los aportes fueron incluidos con las referencias a las personas o instituciones que los habían realizado.

Como parte de ese proceso de participación ciudadana, también para los pueblos originarios la discusión y redacción de ese proyecto fue un hito central en lo que respecta a abrir posibilidades de participación en la planificación general del sistema de medios: fue, como dijimos, el momento en que parte de los movimientos indígenas de Argentina manifestaron públicamente su derecho a tener derechos a la comunicación y su derecho a definir los modos en que querían ser reconocidos como sujetos de derecho en materia de comunicación. Y fue el momento en que, no sin negociaciones y discusiones, esas definiciones pasaron a formar parte del marco legal que regula los sca en Argentina.

\section{Conclusiones: transformaciones políticas y nuevos desafíos}

En diciembre de 2015, Argentina vivió un cambio de gobierno, y asumió el presidente Mauricio Macri. A pocos días de asumir, el mandatario dejó clara su intención de finalizar con las políticas de comunicación que había implementado la gestión anterior. El primer paso fue disolver el AFSCA. En enero de 2016, a través del Decreto 267/15, creó el Ministerio de Comunicaciones y, bajo su órbita, el Ente Nacional de Comunicaciones (Enacom). Ese ente disolvió y unificó al AFSCA y a la Autoridad Federal de Tecnologías de la Información y las Comunicaciones (AFTiC). ${ }^{28}$ También disolvió el Consejo Federal de Comunicación Audiovisual, órgano creado por la Ley de sca en el cual había, entre otros, un representante indígena. El Enacom contempla un directorio conformado, en su mayoría, por miembros designados por el PEN.

Luego, el gobierno anunció que una comisión comenzaría a trabajar en un anteproyecto de Ley de Comunicaciones Convergentes, que reemplace a la Ley de sca y a la Ley 27078 Argentina Digital. En julio de 2016, el Enacom presentó los “17 principios que regirán la Ley de Comunicaciones Convergentes". Allí establece tres tipos de prestadores: de gestión estatal, privados sin fines de lucro y privados con fines de lucro. Desaparecerían, así, los sujetos de derecho público no estatal, entre los cuales están los indígenas. Estos, en cambio, se mencionan en el punto 17:

[...] se fomentará el desarrollo de los medios comunitarios como una herramienta facilitadora de la información y comunicación de las poblaciones con singularidad cultural, social o en representación de colectivos diversos, poblaciones distantes o de difícil acceso, dándoles voz propia y promoviendo el acceso de las mismas a educación, desarrollo social y diversidad cultural y lingüística, como así también, se incentivarán mecanismos de financiación para los medios de zonas rurales, de zonas de frontera y de pueblos originarios.

28 La AFTIC se creó en diciembre de 2014, a partir de la Ley 27078 Argentina Digital, para trabajar en el desarrollo de las tecnologías de la información y las comunicaciones en Argentina. 


\section{DISERTACIONES}

ESTUDIOS

Comunicación indigena en América Latina

ISSN: 1856-9536

Doi: http://dx.doi.org/10.12804/revistas.urosario.edu.co/disertaciones/a.5479

Volumen 11, Número 2 / Julio-diciembre 2018

Versión PDF para imprimir desde

http://revistas.urosario.edu.co/index.php/disertaciones

Ese artículo limita el sentido de los medios comunitarios e incluye a los pueblos originarios en ese sector, lo cual va contra lo demandado por los indígenas. Además, vuelve a una concepción proteccionista de dichos pueblos y de los medios comunitarios, afirmando, a modo de oxímoron, que se busca "darles voz propia".

Simultáneamente, otras líneas de acción en la materia afectan, entre otros, a los pueblos originarios. Si bien entre 2016 y 2017 se otorgaron quince autorizaciones a nuevos prestatarios de scA indígenas, ${ }^{29}$ se limitó la implementación de los Fomeca (se demoraron o negaron pagos de Fomeca otorgados y se demoró la apertura de nuevas convocatorias), impidiendo a esos prestatarios acceder al equipamiento y capacitación. Simultáneamente, dejaron de implementarse líneas de financiamiento que otros organismos del Estado desarrollaban para medios indígenas.

Esto ha confluido en que esos medios se hallen en una situación de alta incertidumbre y vulnerabilidad.

Ello fue objeto de debate, por ejemplo, en el II Encuentro de Comunicación Campesina e Indígena, organizado por la Defensoría del Público de Servicios de Comunicación Audiovisual en 2016. ${ }^{30}$ Allí, representantes de emisoras campesinas e indígenas plantearon que sus equipos están arruinándose y no pueden comprar nuevos. Además, una discusión central tuvo que ver con las críticas a los "17 puntos" presentados por el Enacom y las estrategias por adoptar frente a la posibilidad de que se elabore un nuevo proyecto de ley que regule los medios. Parte de los(as) comunicadores(as) indígenas plantearon que debía elaborarse un comunicado público defendiendo los derechos particulares reconocidos a los pueblos originarios en la Ley de scA. Mientras que otros afirmaron la importancia de fortalecer articulaciones con medios comunitarios, argumentando que en el actual escenario nacional la distinción podría generar divisiones y debilidad política. Tal vez, postulamos, ambas cuestiones no sean contradictorias, ya que la posibilidad de revindicar la continuidad de los derechos reconocidos a los pueblos indígenas no excluye la lucha por la ampliación de derechos a otros actores (como los medios campesinos y comunitarios). Por el contrario, quizá la construcción de condiciones para el éxito de esas reivindicaciones dependa de que se sustenten, como ya lo han hecho en 2009, en el objetivo de la universalización del derecho a la comunicación, lo cual presupone aspirar a la extensión de ese derecho mediante contratos que incluyen deliberación y acuerdos entre los diversos grupos sociales.

Más allá de esta postulación, una cuestión es clara: el escenario político está produciendo transformaciones en las relaciones sociales que configuran las condiciones de ejercicio del derecho a la comunicación, y ello exige nuevas formas para la disputa (nunca clausurada) en torno a ese derecho.

\section{Referencias}

1. Bartolomé, M. (2006). Procesos interculturales. Antropología política del pluralismo cultural en América Latina. México: Siglo xxı.

2. Becerra, M., \& Mastrini, G. (2012). La concentración mediática. Recuperado de https://martinbecerra.wordpress.com/2012/02/22/la-concentracion-mediatica/

29 https://www.enacom.gob.ar/normativas

30 El Encuentro tuvo lugar en Buenos Aires en el mes de agosto, y reunió a representantes de 70 experiencias de comunicación campesinas e indígenas del país. 


\section{DISERTACIONES}

ESTUDIOS

Comunicación indígena en América Latina

ISSN: 1856-9536

Doi: http://dx.doi.org/10.12804/revistas.urosario.edu.co/disertaciones/a.5479

Volumen 11, Número 2 / Julio-diciembre 2018

Versión PDF para imprimir desde

http://revistas.urosario.edu.co/index.php/disertaciones

3. Briones, C. (2015). Políticas indigenistas en Argentina: entre la hegemonía neoliberal de los años noventa y la 'nacional y popular' de la última década. Antípoda. Revista de Antropología y Arqueología, (21), 21-48.

4. Briones, C., Delrio, W., Lanusse, P., Lazzari, A., Lorenzetti, M., Szluc, A., \& Vivaldi, A. (2006). Diversidad e interculturalidad como construcciones sociohistóricas. En A. Ameigeiras \& E. Jure (Comps.), Diversidad cultural e interculturalidad (pp. 255-264). Buenos Aires: Prometeo-ungs.

5. Com, S. (2005). Alfonsinismo, contexto sociopolítico y medios de comunicación. En G. Mastrini (Ed.), Mucho ruido, pocas leyes. Economía y políticas de comunicación en la Argentina (1920-2004) (pp. 185-210). Buenos Aires: La Crujía.

6. Córdoba, L. (2013). Medios masivos y ciudadanía: conceptos y prácticas para la democratización del espacio público mediatizado. El caso de la Coalición por una Radiodifusión Democrática (Argentina, 2004-2009) (Tesis Doctorado en Ciencias Sociales, uBA, Buenos Aires, Argentina).

7. De Dios, R., \& Vigil, C. (1985). Diagnóstico participativo de comunidades: la experiencia del Incupo. Chasqui. Revista Latinoamericana de Comunicación, 14, 56-63.

8. Delrio, W. (2010). Memorias de expropiación. Sometimiento e incorporación indígena en la Patagonia (18721943). Buenos Aires: UnQ.

9. Desalvo, A. (2014). El Mocase: orígenes, consolidación y fractura del Movimiento Campesino de Santiago del Estero. Astrolabio, 12, 271-300.

10. Doyle, M. (2013). Los medios masivos de comunicación en las luchas de los pueblos indígenas. Abordajes desde los estudios sobre comunicación en América Latina (Tesis de maestría, Centro de Estudios Avanzados, Universidad Nacional de Córdoba, Córdoba, Argentina).

11. Doyle, M. (2015). Debates y demandas indígenas sobre derechos a la comunicación en América Latina. Temas Antropológicos, (37), 89-118.

12. Doyle, M. (2017). El derecho a la comunicación de los pueblos originarios. Límites y posibilidades de las reivindicaciones indígenas en relación con el sistema de medios de comunicación en Argentina (Tesis doctoral, Facultad de Filosofía y Letras, UBA, Buenos Aires, Argentina).

13. Giordano, M. (2004). Discurso e imagen sobre el indígena chaqueño. La Plata: Al Margen.

14. Gordillo, G., \& Hirsch, S. (Comps.). (2010). Movilizaciones indígenas e identidades en disputa en la Argentina. Buenos Aires: La Crujía.

15. Grillo, O. (2009). Aproximación etnográfica al activismo mapuche. A partir de internet y tres viajes de trabajo de campo (Tesis doctoral, voc, España).

16. Guber, R. (2001). La etnografía: método, campo y reflexividad. Buenos Aires: Norma.

17. Guzmán, V. (2011). La participación en los foros por una nueva Ley de Servicios de Comunicación Audiovisual en Argentina. El caso de los pueblos indígenas/originarios. Recuperado de http://www.derecom.com/ numeros/articulo0507.html

18. Kejval, L. (2013). Significaciones en torno a las radios comunitarias, populares y alternativas argentinas (Tesis de maestría, uBA, Buenos Aires, Argentina).

19. Kropff, L. (2004). 'Mapurbe': jóvenes mapuche urbanos. Kairós, (14), 1-12. 


\section{DISERTACIONES}

ESTUDIOS

Comunicación indígena en América Latina

ISSN: 1856-9536

Doi: http://dx.doi.org/10.12804/revistas.urosario.edu.co/disertaciones/a.5479

Volumen 11, Número 2 / Julio-diciembre 2018

Versión PDF para imprimir desde

http://revistas.urosario.edu.co/index.php/disertaciones

20. Lenton, D. (2005). De centauros a protegidos. La construcción del sujeto de la política indigenista argentina desde los debates parlamentarios (1880-1970) (Tesis doctoral, Facultad de Filosofía y Letras, UBA, Buenos Aires, Argentina).

21. Lenton, D. (2015). Notas para una recuperación de la memoria de las organizaciones de militancia indígena. Revista Identidades, (8), 117-155.

22. Lizondo, L. (2015). Comunicación con identidad o comunicación comunitaria. El caso de la FM La Voz Indígena (Tesis de maestría, Universidad Nacional de La Plata, La Plata, Argentina).

23. Loreti, D., \& Lozano, L. (2014). El derecho a comunicar. Los conflictos en torno a la libertad de expresión en las sociedades contemporáneas. Buenos Aires: Siglo xxı.

24. Mastrini, G. (Ed.). (2005). Mucho ruido, pocas leyes. Economía y políticas de comunicación en la Argentina (1920-2004). Buenos Aires: La Crujía.

25. Mata, M. (1999). De la cultura masiva a la cultura mediática. Diálogos de la Comunicación, (56), 80-91.

26. Mombello, L. (2002). Evolución de la política indigenista en Argentina en la década de los noventa. EE. uu.: Clapso.

27. Müller, A., Elbirt, A., \& Leal, C. (2015). Trascender los cerros. Promoción y aplicación de la Ley de Servicios de Comunicación Audiovisual en ámbitos rurales y de la agricultura familiar en Salta. En R. Burgos (Comp.), Comunicación popular y alternativa en contextos de frontera: mapeo de actores y experiencias en sectores populares de Salta (pp. 167-188). Córdoba: Gráfica 29 de Mayo.

28. Nussbaumer, B. (2014). Pueblo, territorio y autonomía. Tensiones en los modos de construcción de los indígenas como sujetos de derecho en Argentina. Trabajo y Sociedad, (23), 485-506.

29. Radovich, J. (2014). La percepción de los pueblos indígenas en los medios masivos de comunicación. En C. Guarini \& M. de Angelis (Comps.), Antropología e imagen. Pensar lo visual (pp. 156-171). Buenos Aires: Sans Soleil.

30. Rossi, D. (2006). Acceso y participación en el nuevo siglo. Limitaciones de la política, condicionamientos de los conglomerados. Buenos Aires: Cátedra Políticas y Planificación de la Comunicación-uBA. Mimeo.

31. Roulet, F., \& Garrido, M. (2011). El genocidio en la historia: ¿un anacronismo? Corpus. Archivos Virtuales de la Alteridad Americana, 1(2), 1-9.

32. Tamagno, L. (2013). Políticas indigenistas en Argentina, alcances y límites. Demandas, luchas, representaciones y nuevas configuraciones etnopolíticas. Runa, 34(1), 9-12.

33. Trentini, F., Valverde, S., Radovich, J., Berón, M., \& Balazote, A. (2010). "Los nostálgicos del desierto": la cuestión mapuche en Argentina y el estigma en los medios. Revista Cultura y Representaciones Sociales, 4(8), 186-212.

34. Trinchero, H. (2009a). Pueblos originarios y políticas de reconocimiento en Argentina. Papeles de Trabajo, (18), 1-17.

35. Trinchero, H. (2009b). Las masacres del olvido. Napalí y Rincón Bomba en la genealogía del genocidio y racismo de Estado en Argentina. Runa, 23(1), 45-60.

36. Valko, M. (2007). Los indios invisibles del Malón de la Paz: de la apoteosis al confinamiento, secuestro y destierro. Buenos Aires: Ediciones Madres de Plaza de Mayo.

37. Yanniello, F. (2014). Descolonizando la palabra. Los medios de comunicación del pueblo mapuche en Puelmapu. Buenos Aires: La Caracola. 


\section{Documentos}

1. Organizaciones de Pueblos Originarios (2009). Propuesta de inclusión del derecho a la comunicación con identidad de organizaciones de los pueblos originarios en el anteproyecto de Ley de Servicios de Comunicación Audiovisual. Documento elaborado en el Encuentro Nacional de Organizaciones de Pueblos Originarios, Buenos Aires. Mimeo.

2. AFCA. (2011). Listado de autorizaciones a comunidades indígenas. Inédito.

3. DPSCA. (2015). Informe sobre denuncias presentadas a la Defensoría sobre representaciones mediáticas lesivas para con pueblos originarios. Inédito.

4. DPSCA. Resolución 140/2014.

5. Inadi. (2005). Hacia un plan nacional contra la discriminación. Diagnósticos y propuestas.

6. Ley Nacional 26522 de Servicios de Comunicación Audiovisual (octubre 2009).

7. Ponencias presentadas en Cámara de Diputados de la Nación, plenario de comisiones de Comunicaciones e Informática, Presupuesto y Hacienda y Libertad de Expresión. Audiencias públicas desarrolladas entre el 8 y 11 de septiembre de 2009 para el tratamiento del Proyecto de Ley de Servicios de Comunicación Audiovisual. Recuperado de http://www1.hcdn.gov.ar/radiodifusion/pdf/ponencias/ponencias.pdf

8. Resolución 403-Comfer/04.

9. Resolución 576-Comfer/01.

10. Resolución 705-Comfer/00.

11. Serpac. (s. a.). Memorias de la tierra. Documento del Servicio Pastoral para la Comunicación del Obispado de Neuquén. Mimeo.

\section{Sitios web}

1. http://afsca.gob.ar/experiencias-anteriores/

2. https://www.enacom.gob.ar/normativas 